\title{
CULTURA E SUBCULTURA POLICIAL: LIMITES PARA A RESOLUÇÃO PACÍFICA DE CONFLITOS
}

\author{
POLICE CULTURE AND SUBCULTURE: LIMITS FOR THE PEACEFUL CONFLICT RESOLUTION
}

CULTURA Y SUBCULTURA POLICIAL: LÍMITES PARA LA RESOLUCIÓN PACÍFICA DEL CONFLICTO

\author{
Vera Karam de Chueiri \\ Pós-doutora pela Yale University. Doutora em filosofia pela New School for Social Research. Docente da \\ graduação e pós-graduação da Faculdade de Direito da UFPR. \\ Orcid: https://orcid.org/0000-0001-7069-5272. \\ E-mail: vkchueiri@gmail.com.
}

\author{
Pedro Paulo Porto de Sampaio \\ Doutorando em políticas públicas pela UFPR. Mestre em políticas públicas pela UFPR. \\ Orcid: https://orcid.org/0000-0002-0606-473x. \\ E-mail:pppsampaio@gmail.com.
}

\begin{abstract}
RESUMO
O presente artigo investiga os reflexos das subculturas nas instituições policiais, e de que maneira limitam posturas voltadas à polícia comunitária e à resolução pacífica de conflitos. Como etapa inicial do estudo, analisa-se o alcance do mandato policial e o problema do enforcement. Em seguida, o artigo examina o desafio da cultura e da subcultura policial, desde a formação nas academias até o cotidiano profissional. Além disso, observa a influência do Movimento Lei e Ordem e do Programa Tolerância Zero, o que determina a manutenção de um modelo tradicional de policiamento, eminentemente reativo e repressivo — o que, por vezes, repercute na violação de direitos e garantias fundamentais. A partir desses subsídios, busca-se apresentar elementos que fortaleçam os mecanismos de atuação comunitária como alternativa para a superação desses processos culturais arraigados. Com o foco na perspectiva comunitária e orientada para a solução de problemas, estima-se uma mudança no modelo de atuação policial para uma abordagem proativa e baseada na resolução pacífica de conflitos.
\end{abstract}

Palavras-chave: Subculturas. Polícia comunitária. Resolução pacífica de conflitos.

\begin{abstract}
This article investigates the reflexes of subcultures in police institutions, and how they limit attitudes towards community police and the peaceful resolution of conflicts. As an initial stage of the study, the scope of the police mandate and the problem of enforcement are analyzed. Then, the article analyzes the challenge of police culture and subculture, from training in the academies to the professional routine. In addition, it observes the influence of the Law and Order Movement and the Zero Tolerance Program, thus determining the maintenance of a traditional policing model, which is eminently reactive and repressive, which sometimes affects the violation of fundamental rights and guarantees. Based on these subsidies, we seek to present elements that strengthen the mechanisms of community action as an alternative to overcome these entrenched cultural processes. With a focus on the community perspective and oriented towards problemsolving, a change in the model of police action is expected to move towards a proactive approach based on peaceful conflict resolution.
\end{abstract}

Keywords: Subcultures. Community police. Peaceful conflict resolution. 


\section{RESUMEN}

El presente artículo investiga los reflejos de las subculturas en las instituciones policiales y de qué manera limitan iniciativas destinadas a una policía comunitaria y a la resolución pacífica de conflictos. Como etapa inicial del estudio, se analiza el alcance de la orden policial y el problema del enforcement. Luego, el artículo examina el reto de la cultura y de la subcultura policial, desde la formación en las academias hasta el ejercicio profesional cotidiano. Además, se observa la influencia del Movimiento Ley y Orden, del Programa Tolerancia Cero, que determina la permanencia de un modelo tradicional de trabajo policial, eminentemente reactivo y represivo - lo que, muchas veces, repercute en la violación de derechos y garantías fundamentales. A partir de esos insumos, se trata de presentar elementos que fortalezcan los mecanismos de participación comunitaria como alternativa para la superación de esos procesos culturales arraigados. Con atención en la perspectiva comunitaria y orientada a la solución de problemas, se espera un cambio en el modelo de acción policial hacia un acercamiento proactivo y basado en la resolución pacífica de conflictos.

Palabras-clave: Subculturas. Policía comunitaria. Resolución pacífica de conflictos.

\section{INTRODUÇÃO}

Um dos desafios da sociedade contemporânea nas cidades brasileiras são a escalada da violência e da criminalidade e a maneira como esse fenômeno repercute nas comunidades. Estudos demonstram a elevação de assassinatos e de outros crimes violentos nos últimos 35 anos; assim, de acordo com estatísticas oficiais (BRASIL, 2018), o país tornou-se o campeão mundial no tema violência urbana (FERREIRA; MARCIAL, 2015).

Os atores públicos, especialmente os membros das agências policiais, procuram respostas a essa realidade social; entretanto, de maneira sistemática, adotam medidas que em algum momento perpassam pela reprodução de comportamentos conceitualmente não tolerados pelo próprio Estado e por suas estruturas de poder; viola-se, assim, direitos e garantias fundamentais e age-se unicamente como um sistema amparado em uma cultura de controle (GARLAND, 2008). Essa fragilidade, que notadamente recai sobre as instituições policiais, potencializa o que Miliband (1982, p. 102) denominou de papel decisivo de repressão estatal pelo "uso da violência crua" por meio da chamada "rotinização do conflito".

Assim, é a partir desse indicativo que o presente artigo objetiva discutir a necessidade de um "novo olhar" sobre as instituições policiais, principalmente na perspectiva dos processos culturais, os quais têm se revelado potencialmente responsáveis pelo entrincheiramento de modelos comunitários e orientados para a resolução pacífica de conflitos. 
São etapas essenciais do estudo: o exercício do mandato policial; os limites do uso da força; e a análise de como as subculturas nas instituições policiais possibilitam o desrespeito aos direitos fundamentais.

Do mesmo modo, serão investigadas as possíveis influências dos movimentos Lei e Ordem e do Programa Tolerância Zero, legitimando assim a retórica discursiva e a opção do "combate" ao crime ancorada no punitivismo midiático, o que levou Garland (2008, p. 72) a alertar sobre o perfil de política criminal como "uma postura ou tática política, adotada para a obtenção de dividendos políticos de curto prazo".

Como parte final, será abordada a polícia comunitária como uma alternativa à superação do discurso, por vezes, dominante no imaginário popular e em setores da polícia, que entende como justificada essa prestação de serviço público - custe o que custar — mesmo que em desarmonia com direitos fundamentais.

\section{A extensão do mandato policial}

De acordo com Goldstein (2003, p. 127), "a polícia exerce um amplo poder discricionário ao conduzir suas múltiplas funções". Para o autor, há uma relação direta entre a qualidade do serviço policial e o critério de utilização desse poder. Segundo Goldstein, no passado a opinião do público e da polícia era de que esta não tinha liberdade discricionária, pois sua função estava estritamente vinculada ao que previa a lei; ao agir assim, a polícia incorporava o que dela era esperado pelos legisladores, pelos tribunais e por um significativo contingente da opinião pública.

Entretanto, por trás do discurso oficial, "de modo secreto e com um ar de ilegitimidade e impropriedade, por necessidade, a polícia trabalhava de maneira muita mais solta e informal — fazendo escolhas frequentes e trabalhando com ampla liberdade discricionária." (GOLDSTEIN, 2003, p. 127).

Essa realidade dicotômica da polícia, por um lado sustentando um discurso oficial, de subordinação à lei, e, por outro, obscuro, com maior grau de liberdade discricionária, impediu um desenvolvimento saudável das instituições policiais (GOLDSTEIN, 2003).

Destarte, a polícia se viu forçada a violar a lei para desempenhar seu trabalho "e premiou a duplicidade nas relações dos policiais uns com os outros e com a comunidade." (GOLDSTEIN, 2003, p. 128). 
Nesse contexto, os problemas advindos do uso da força e do monopólio da violência são estudados por Muniz e Proença Júnior, a partir da perspectiva do mandato policial. Mediante a análise de uma vasta bibliografia sobre o tema, os autores contextualizam o papel da polícia, na tentativa de superar a "dicotomia entre oficial da lei e oficial da ordem. " (MUNIZ; PROENÇA JÚNIOR, 2014, p. 406); ou seja, do dilema enfrentado entre lei e ordem, e que traduz em grande parte os recentes rumos no campo de segurança pública adotados por governos e por organizações policiais.

Para os autores, seguindo a linha de Bittner (1990),

A polícia é equipada tanto em termos de equipamento quanto de preparo para o exercício de seu mandato. É autorizada porque lhe são conferidos respaldo legal e consentimento social para policiar. E responde por qualquer exigência, qualquer situação de perturbação de um determinado status quo que corresponde, em termos amplos, à paz social (MUNIZ; PROENÇA JÚNIOR, 2014, p. 406).

Tal conceituação descrita por Muniz e Proença Júnior (2014, p. 407), a partir da construção de Bittner, supera o entendimento de que a função da polícia se resuma à mera atividade de policiamento, afastando assim uma visão simplista, em prol da plenitude do mandato policial, que integraria as funções de "atender a emergências, respaldar a lei, sustentar a ordem pública, preservar a paz social, ou desempenhar quaisquer outras funções sociais, de forma reativa ou preemptiva".

Muniz e Proença Júnior (2014, p. 407) abordam ainda o "problema do enforcement". Os autores questionam o que distingue o uso da força pela polícia e por demais atores, e por que a polícia é chamada quando o uso da força se revela útil. Para os autores, "a polícia é uma resposta ao desafio de produzir enforcement sem que este leve à tirania ou passe a servir interesses particulares”. Assim, “o uso de força pela polícia tem um propósito político distintivo e invariante: produzir alternativas de obediência com consentimento social, sob o Império da Lei. " (MUNIZ; PROENÇA JÚNIOR, 2014, p. 407).

\section{O desafio da cultura e (sub)cultura policial}

Para a obtenção de equilíbrio entre exercício do mandato policial e uso da força, é essencial compreender como essa interface ocorre, principalmente sob a ótica dos processos culturais incorporados às agências policiais, as quais, na visão de Goffman (1974), podem se caracterizar como instituições totais. 
Para Goffman (1974), instituições totais são aqueles locais, residências ou trabalho cujos indivíduos vivem em situação semelhante, levando uma vida fechada, administrada de maneira formal e separada da sociedade por um período amplo. O autor retrata que a tendência de fechamento é algo inerente às instituições, sendo que o “'fechamento' ou seu caráter total é simbolizado pela barreira à relação social com o mundo externo" (GOFFMAN, 1974, p. 16).

Ratton (2007, p. 141), em estudo sobre os aspectos organizacionais e culturais da polícia, destaca como tema relevante da teoria organizacional o de que "diferentes ocupações desenvolvem maneiras diversas de percepção e resposta ao seu ambiente externo". Assim, para o autor, tal formulação geral, aplicada às polícias, aponta traços comuns a essas organizações, consistentes nas ideias de perigo, autoridade e eficiência, o que identifica então a ideia da cultura policial.

O perigo circunda a atividade policial. A rotina desse ofício submete o seu integrante a ameaças potenciais, desde ações de investigação até a dissuasão de atos opostos à legislação. Essa situação permite que a polícia se valha do aparato da força, por meio de seu uso legítimo, mas que, por vezes, se traduz no uso ilegítimo (RATTON, 2007).

Aliado ao perigo, o exercício da autoridade também é elemento determinante da cultura policial. Sobre esse elemento, Ratton (2007) destaca a expectativa que se gera dentro e fora da polícia acerca das imposições típicas da sociedade moderna, em que se impõe o exercício da autoridade acerca do que o autor denomina de "clientela da polícia".

O terceiro elemento que sintetiza a cultura da polícia trata da eficiência. Tal elemento considera a vigilância contínua da sociedade, na busca de respostas estatais aceitáveis, seja na resolução de casos polêmicos, ou mesmo na redução dos índices de criminalidade.

Assim, esses três elementos conjugados formam o que Ratton (2007, p. 142) indica como uma "equação sociológica", visto que "o policial é um profissional que lida permanentemente com situações perigosas em que se criam exigências de manutenção da autoridade e pressões para a demonstração de eficiência".

A construção de Monet (2006, p. 157), da “polícia como vítima de seu mito”, alinhase ao estudo da cultura policial. O autor aponta que estudos levados a efeito na América do Norte e na Grã-Bretanha sobre eficácia policial no controle da criminalidade indicam que 
“tudo, na sociedade, conspira para dar à polícia a imagem de uma instituição inteiramente voltada para a luta contra o crime e a prisão de criminosos." (MONET, 2006, p. 157).

Segundo o referido autor, os próprios policiais são responsáveis pela difusão do ideário de que são justiceiros ou combatentes do crime, fazendo com que essa representação que a polícia faz de si mesma se mostre redutora e mistificadora. Num primeiro plano redutora, pois a polícia trata de diversos outros problemas, principalmente de ordem social, superando assim a clássica noção de que atua apenas diante da criminalidade. É mistificadora, também, visto que induz o policial a acreditar que detém o monopólio da força, de maneira ilimitada e incondicionada, fazendo-o crer que a polícia é igual à segurança e, quanto mais polícia existir, mais segurança existirá (MONET, 2006).

Para Reiner (2004, p. 132), "culturas são complexos conjuntos de valores, atitudes, símbolos, regras e práticas, que emergem quando as pessoas reagem às exigências e situações que enfrentam". O autor afirma que a "cultura da polícia, como qualquer outra, não é monolítica", mas fruto de experiências anteriores, modelando-se por pressões estruturais dos atores e do ambiente (REINER, 2004, p. 132).

Como aspectos principais da cultura policial, e de maneira semelhante a Ratton (2007), Reiner (2004) vale-se do texto clássico de Jerome Skolnick, de 1966, sobre a personalidade do trabalho policial. Adverte que a esse modelo básico devem ser adicionadas as variações, típicas, de cada uma das forças policiais. A partir dos estudos de Skolnick, Reiner (2004, p. 135) destaca que a "personalidade do trabalho policial não é um fenômeno psicológico individual (como, erroneamente, pode sugerir o termo (personalidade'), mas uma cultura socialmente gerada". Assim, conforme Skolnick, a cultura policial é uma combinação de duas vertentes do papel policial, "o perigo e a autoridade, que devem ser interpretadas à luz de uma pressão 'constante' de parecer eficiente" (SKOLNICK, 1966, p. 44 apud REINER, 2004, p. 135).

No que tange à vertente do perigo, Reiner destaca que não se resume às estatísticas sobre danos físicos, até mesmo porque outras profissões, como na mineração ou construção civil, os profissionais que nelas atuam estão mais expostos a riscos e doenças decorrentes do trabalho. A diferença reside na peculiaridade do serviço policial, uma vez que o operador está submetido à imprevisibilidade do enfrentamento em situações limítrofes, como ameaças de ataques súbitos de outras pessoas, e não de riscos inerentes a fatores físicos e ambientais, em certa medida calculáveis (REINER, 2004). 
Por sua vez, conforme destaca o autor, “o perigo é inerente à autoridade que é parte integrante do meio policial", isso porque "ao representar a autoridade, tendo por trás o uso potencial da força legitimada, o policial enfrenta o perigo proveniente daqueles que resistem ao exercício da tal autoridade. " (REINER, 2004, p. 136).

O autor retrata que, não obstante a presença constante do perigo, a polícia inglesa tradicionalmente tem se pautado pela diminuição do uso da força, na busca de transformar o poder em autoridade, fazendo do policial um símbolo individual, de impessoalidade, provocando nos cidadãos um sentimento de aceitação universal à lei (REINER, 2004). Assim, esses elementos do perigo e da autoridade são interdependentes no mundo policial, os quais geram uma "série de regras de adaptação, receitas, retórica e rituais. " (REINER, 2004, p. 136).

Aliados a esses dois elementos, Skolnick propõe ainda um terceiro, de natureza ambiental, que se traduz na pressão direta sofrida, em cada integrante da polícia, para que seja mais eficiente do que cumpridor da lei, quando ambos os valores são colocados em conflito (REINER, 2004). Essas influências do ambiente variam de tempos em tempos e, principalmente, quando instrumentalizadas por estatísticas oficiais.

Sobre essas pressões do ambiente, produzindo um paradoxo entre eficiência e violação de direitos e garantias, Reiner (2004, p. 136) destaca que, ao se optar pelo recrudescimento da resposta estatal, abriu-se espaço para o ideário coletivo da "manutenção de ordem e do combate ao crime".

Dias Neto (2000) trata da chamada "subcultura policial”. De acordo com o autor, "a idealização da função policial, reconhecida somente em seus aspectos criminais, e a condição de isolamento da polícia são os principais fatores do fortalecimento da chamada subcultura policial” (DIAS NETO, 2000, p. 35). Para ele, a ocorrência de culturas ocupacionais é um fenômeno relativamente frequente e não necessariamente prejudicial ao regular funcionamento das instituições. "Esses códigos internos de valores e crenças expressam sentimentos de solidariedade e de autoproteção, especialmente entre profissionais que atuam sob pressão, em ambientes permeados por hostilidades e riscos." (DIAS NETO, 2000, p. 35).

Nesse contexto, a temática da subcultura é habitualmente introduzida na sua modalidade negativa, o que demonstra os obstáculos à tentativa de aprimoramento institucional (DIAS NETO, 2000). Há um consistente movimento que expressa, em alguns 
casos, a preocupação do policial de agir discretamente, para ficar longe da fiscalização de supervisores; frases como "stay out of trouble" [fique longe de problemas] ou "lay low" [deixe passar] demonstram a intenção de evitar pressões tidas como “desnecessárias", como aquelas decorrentes de um aumento súbito de produtividade, em certo mês, podendo gerar expectativas tanto para o próprio policial quanto para seus colegas (DIAS NETO, 2000).

Garland (2008) indica que nas últimas décadas ocorreram transformações tanto na estrutura social quanto na sensibilidade cultural, basicamente oriundas de uma nova experiência coletiva com a insegurança, o que fez abrir espaço para mudanças nas formas de controle do crime. Assim, "as tendências sensoriais e emocionais desta experiência coletiva foram tomadas, retrabalhadas e infletidas para resultados específicos pela classe política e por formadores de opinião. "(GARLAND, 2008, p. 311).

Considerando que as estratégias são desenvolvidas e legisladas no âmbito político, para se tornar viáveis dependem de aceitação popular, motivo pelo qual há uma relação direta entre a cultura policial, a extensão do mandato policial e a percepção geral, da população, sobre direitos humanos.

Schabbach (2015), em artigo dedicado a investigar as representações sobre direitos humanos por policiais civis no estado do Rio Grande do Sul, destaca que, no imaginário social, os direitos humanos não são compreendidos, na plenitude, como universais. De acordo com o estudo, pessoas podem até questionar violações de direitos humanos em outros países, mas não se revelam defensoras desses direitos quando violados em seu próprio país.

A autora, no artigo intitulado Com a Lei Debaixo do Braço, reforça o aspecto cultural da opção pelo conflito e pela violência que demonstram os policiais, desde os períodos iniciais da formação, daqueles recém-integrados à instituição, o que nos indica um sentimento relativamente coletivo com relação aos direitos humanos (SCHABBACH, 2015). Para Schabbach (2015, p. 160), “embora atinentes a qualquer indivíduo, os direitos humanos são cultural e politicamente ressignificados em contextos sociais específicos".

Sobre a cultura policial, Schabbach (2015, p. 163) afirma que "a atuação policial é impregnada de valores derivados de práticas sociais e culturais mais amplas", sendo que “o policial sente-se protegido por uma cultura institucional que inclui a violência como possibilidade para conter transgressões". 
Bittner (2003) indica dois aspectos que influenciaram o modo como a população observa a polícia. O primeiro deles é o estigma, diante do contato reiterado com o crime e a desordem, ou seja, com o mal, que faria da polícia uma "ocupação corrompida" (BITTNER, 2003, p. 98). Além disso, a população identifica a polícia como organização obrigada a agir com presteza e despida de uma reflexão mais apurada em situações envolvendo conflitos humanos de natureza complexa.

Ainda sob a ótica da profissão policial e a sua cultura, tanto Poncioni (2003) quanto Hagen (2006) apontam que a profissão policial deriva de um grupo social específico, com sentimentos arraigados de pertencimento e identidade, cujas ações nutrem valores e crenças próprias, o que por vezes faz esses indivíduos se dissociarem de outros estamentos sociais, principalmente diante das condições precárias de trabalho, dos salários baixos, das complexas habilidades constantemente exigidas e, inclusive, da percepção de abandono por parte da sociedade e de suas próprias instituições.

Na Pesquisa Nacional por Amostragem Domiciliar sobre Atitudes, Normas Culturais e Valores em Relação à Violação de Direitos Humanos e Violência no Brasil, Cardia (2012) aponta que direitos humanos não são compreendidos como universais ou inalienáveis e, até mesmo, que a percepção geral sobre esses diretos humanos varia conforme o contexto, considerando se os casos são concretos ou abstratos, como, por exemplo, quando envolve um amigo ou familiar.

Nesse estudo, elaborado em parceria com o Instituto de Pesquisa Econômica Aplicada (Ipea), evidenciou-se que há uma maior concordância com o uso da violência pela polícia conforme a natureza do delito. Práticas como ameaçar com palavras e agredir fisicamente para obter informações têm maior aceitação em crimes como sequestro, estupro ou tráfico de drogas, ao passo que crimes como roubo a motoristas em semáforos ou mesmo o uso de drogas têm uma menor aceitação em episódios de violência policial (CARDIA, 2012).

Brito e Souza (2004), no mesmo sentido, destacam uma certa ambiguidade com relação à percepção social acerca da violência, principalmente por parte das organizações policiais. Para os autores, "se, por um lado, ela solicita, autoriza e legitima tais modos de ação frequentemente para a solução de seus problemas pessoais, por outro lado, é capaz de se indignar e denunciá-las, quando deles de torna vítima. " (BRITO; SOUZA, 2004, p. 308). 
Teresa Caldeira (1991) procura desvendar em que momento da história, na redemocratização, os direitos humanos passaram a transmitir uma conotação negativa, principalmente diante do crescimento da violência, criminalidade e de um outro fenômeno, a privatização da segurança.

Segundo Caldeira (1991), durante o período de ditadura militar, os defensores de direitos humanos não eram estigmatizados, no ideário coletivo, por defender opositores do regime que se encontravam na condição de presos políticos, notadamente aqueles pertencentes à classe média. Entretanto, após a anistia, em 1979, com a libertação dos presos políticos, esses ativistas de direitos humanos passaram a atuar na defesa de presos comuns. Esses grupos, principalmente de religiosos e juristas de classe média e alta, acabaram estigmatizados, fenômeno que se observa ainda nos dias atuais.

Caldeira (1991) retrata a experiência do Governo Franco Montoro (1983-1987), em São Paulo, que, apesar da tentativa inicial de adotar ações direcionadas a controlar abusos policiais, reformas das organizações de segurança pública, bem como humanizar as prisões, passou a sofrer severas críticas de grupos políticos de direita, representantes de policiais e órgãos de comunicação, principalmente aqueles dedicados a divulgar fatos criminosos. Essa campanha oposicionista, cuja bandeira alardeava que os direitos humanos representavam privilégios para bandidos, obteve relativo sucesso na década de 1980. A autora relata que, apesar de uma diminuição dessa rejeição na década de 1990, diante da consolidação democrática no país, ainda permanecem, no imaginário social, consistentes elementos que antagonizam a resposta estatal ao crime e a proteção aos direitos humanos.

Reiner (2004) aponta que os policiais sofrem pressões, notadamente de natureza política, para que apresentem resultados, principalmente na solução de casos, o que invariavelmente deságua na expansão de seus poderes e na violação de direitos e garantias de suspeitos.

O autor ainda destaca que as culturas podem sofrer variantes particulares, chamadas de subculturas, "que podem se distinguir no interior da cultura policial mais geral, geradas por experiências distintas associadas a posições estruturais específicas, ou por orientações especiais que os policiais trazem de sua biografia e histórias anteriores" (REINER, 2004, p. 132).

Desse modo, ao lado dos elementos centrais que orientam a atuação policial, concebendo assim os processos culturais que caracterizam essas agências estatais, outro 
aspecto a ser desvelado é a influência de movimentos penais expansionistas, havidos principalmente após derrocada do Estado do Bem-Estar Social, na década de 1970.

\section{As influências do movimento lei e ordem e do programa tolerância zero}

A compreensão dos modelos de atuação policial parte da observação quanto aos efeitos gerados pelos movimentos político-criminais, e de que maneira, ao longo do tempo, políticas públicas no campo da segurança têm conduzido o padrão de resposta estatal ao fenômeno do crime, possibilitando assim, o que Elbert (2011) denominou de "populismo penal", consistente em ações de autolegitimação dos governos e executado por meio de medidas improvisadas, as quais repercutem no modelo de política criminal, dando lugar ao senso comum, à irracionalidade e à busca pela derrota do mal absoluto.

Como decorrência do discurso de tratamento do mal e do enfrentamento do medo, surge a cura, cujo remédio é o agravamento da resposta do aparato oficial, em que se adota o arquétipo de "combate” ao crime, em oposição à prestação de um serviço público, o que faz com que os órgãos policiais se distanciem das efetivas necessidades sociais, reproduzindo-se, assim, modelos conservadores, entre os quais aqueles que incentivam a mera repressão estatal.

Essa opção ficou clara nos Estados Unidos da América, conforme relata Wacquant (2003), durante os anos de 1976 a 1989, em que foram aumentados em mais de $95 \%$ os investimentos no sistema carcerário, enquanto foi reduzida expressivamente a destinação de recursos públicos para educação, saúde e, em especial, para ajudas sociais, com um corte aproximado de $41 \%$.

Na obra Prisões da miséria, Wacquant (2001, p. 7, grifo do autor) resume a realidade nos Estados Unidos da América, em que "a penalidade neoliberal apresenta o seguinte paradoxo: pretende remediar com um 'mais Estado' policial e penitenciário o 'menos Estado' econômico e social que é a própria causa da escalada generalizada da insegurança".

Fruto dessa orientação político-criminal, a concepção de Estado policial e penitenciário a que se refere Wacquant é descrita por Ferrajoli (2002, p. 84, grifo do autor) como reflexo de um movimento penal expansionista, "incondicionado e ilimitado", que se caracteriza, "além de sua excessiva severidade, pela incerteza e imprevisibilidade das condenações e das penas". 
A aplicação superficial do modelo de Goldstein (1979), orientado para o problema, com foco na comunidade, permitiu o surgimento, nos Estados Unidos da América e em outros países, de movimentos penais e policiais expansionistas. De acordo com Wacquant (2001), a partir da obra de James Q. Wilson, Thinking about crime (1975), Charles Murray lançou, em 1984, Losing ground: American social policy (1950-1980), que, juntamente com a obra Law and order (1985), de Ralf Dahrendorf, ofereceu as primeiras bases teóricas daqueles que seriam os mais conhecidos, influentes e difundidos modelos de intervenção estatal-policial: o movimento Lei e Ordem e o programa Tolerância Zero. Esses modelos, que reproduzem elementos da era da reforma policial (DIAS NETO, 2000; WILSON, 1992), acabaram por se espraiar por diversas cidades dos Estados Unidos e pelo mundo.

Segundo Wacquant (2001, p. 22), a obra de Murray, visando a "aplicar os princípios da economia de mercado aos problemas sociais", logo se tornou um clássico, servindo como uma “"bíblia’ para a cruzada contra o Estado Providência”. O autor relata que o presidente estadunidense era o republicano Ronald Reagan, o qual, apesar de deter minoria no Congresso, composto amplamente de democratas, ainda assim unificou as correntes ideológicas e empreendeu uma forte crítica sobre as políticas públicas de ajuda social nos Estados Unidos. De acordo com Reagan, essa política seria responsável pelo aumento da violência urbana, pois recompensaria a inatividade, além de induzir "à degenerescência moral das classes populares", principalmente em face das uniões ditas “ilegítimas", compreendidas como o último dos males das sociedades modernas (WACQUANT, 2001, p. 22).

O filósofo e professor Michael J. Sandel (2012, p. 12), da Universidade de Harvard, retrata esse período como a "era do triunfalismo do mercado", que "começou no início da década de 1980, quando Ronald Reagan e Margaret Thatcher proclamaram sua convicção de que os mercados, e não o governo, é que detinham a chave da prosperidade e da verdade".

Desse período, destaca-se a obra Law and Order, em que Ralf Dahrendorf (1985) trata do que definiu como a "estrada para a anomia". Para o autor, a ausência de uma resposta estatal quanto à violação de uma norma produziria uma anomia no sistema, a qual somente poderia ser superada a partir da adesão a mecanismos de punição efetiva e exemplar. Segundo Dahrendorf (1985), observa-se um declínio das sanções nas sociedades contemporâneas, tornando-se a impunidade cotidiana. 
Partindo desses antecedentes, o prefeito eleito de Nova lorque em 1993, Rudolph Giuliani, resgataria a chamada Teoria das Janelas Quebradas (Broken Windows Theory), de James Q. Wilson e George L. Kelling, originalmente publicada em 1982 na revista Atlantic Monthly. Entretanto, em 1996, o mesmo Kelling, em coautoria com Catherine Coles, escreveria a obra que se tornaria a sustentação para a mudança da política pública de segurança na cidade de Nova lorque - "Fixing broken windows: restoring order and reducing crime in our communities ['Consertando as vidraças quebradas: como restaurar a ordem e reduzir o crime em nossas comunidades']" (WACQUANT, 2001, p. 26).

A administração de Giuliani, com o auxílio do chefe de polícia William Bratton, concebeu então o programa chamado Tolerância Zero, o qual, segundo Shecaira (2009, p. 166), tinha como ideia central "que uma pequena infração, quando tolerada, pode levar ao cometimento de crimes mais graves, em função de uma sensação de anomia que viceja em certas áreas da cidade".

De acordo com Wacquant (2001), o programa Tolerância Zero caracterizou-se como uma abrupta intervenção da força policial, “desembocando em uma aplicação inflexível da lei sobre delitos menores tais como a embriaguez, a jogatina, a mendicância, os atentados aos costumes, simples ameaças e outros comportamentos anti-sociais" (WACQUANT, 2001, p. 26).

Ao lado da repressão às pequenas infrações, o programa também se notabilizou por um expressivo incremento no aparato policial, com uma ampliação de $40 \%$ no orçamento público em cinco anos, atingindo a marca de US\$ 2,6 bilhões. Entre as diversas medidas tomadas, podem-se citar o crescimento do efetivo policial, a demissão de servidores mais antigos, tidos como não tão eficientes, e o aumento exponencial no número de prisões (WACQUANT, 2001).

Wacquant (2001) faz severa crítica à Teoria das Janelas Quebradas, ao afirmar que o movimento foi proposto a partir do início da década de 1990, quando o Manhattan Institute financiou campanha agressiva de reocupação e recuperação dos espaços públicos, como uma forma de afastar a desordem e a marginalização, expondo que o combate diário à pequena delinquência faria recuar as chamadas "grandes patologias criminais", que afetavam o centro do mercado financeiro do mundo.

Para Wacquant (2001, p. 26), “essa teoria, jamais comprovada empiricamente, serve de álibi criminológico para a reorganização do trabalho policial empreendida por William 
Bratton". Essa reorganização, de acordo com o autor, teria como objetivo "refrear o medo das classes médias e superiores - as que votam - por meio da perseguição permanente dos pobres nos espaços públicos (ruas, parques, estações ferroviárias, ônibus e metrô etc.) " (WACQUANT, 2001, p. 26), o que Zaffaroni e Oliveira (2010) denominaram de espetáculo criminal do espetáculo político, em que a classe média identifica qualquer diferente como inimigo.

Ressalte-se que, apesar dos elevados investimentos e das marcas obtidas em Nova Iorque, houve, também, redução dos índices de criminalidade em cidades como San Diego, Boston e Chicago, que mantiveram, por outro lado, uma metodologia da polícia de proximidade, comunitária, sem grandes aumentos de efetivo policial e de recursos públicos. Já Nova Iorque, ao aumentar em cinco vezes o orçamento para a área de segurança, teve reduzidos em um terço os investimentos na área social, com a supressão de aproximados oito mil postos de trabalho (WACQUANT, 2001).

Essa doutrina de Giuliani teve ampla aceitação na cultura estadunidense e, diante dos resultados obtidos, principalmente com o formidável retorno midiático, vários países arvoraram-se a adotar o modelo. Na Argentina (na cidade de Buenos Aires), no México (em várias cidades), na Escócia, na Itália, na África do Sul, na Nova Zelândia, no Canadá e até mesmo no Brasil foi copiado o modelo (WACQUANT, 2001). No Brasil, talvez seja esse um dos principais motivos que impedem a expansão do modelo comunitário e orientado para a resolução pacífica de conflitos.

Em janeiro de 1999, depois da visita de dois altos funcionários da polícia de Nova York, o novo governador de Brasília, Joaquim Roriz, anuncia a aplicação da "tolerância zero" mediante a contratação imediata de 800 policiais civis e militares suplementares, em resposta a uma onda de crimes de sangue do tipo que a capital brasileira conhece periodicamente (WACQUANT, 2001, p. 31).

Essa ação integrada de força da polícia de Nova lorque teve seus efeitos colaterais, que, a rigor, mitigaram o "sucesso" auferido na redução dos índices de criminalidade na Big Apple. Dados da National Urban League apontam que em dois anos foram detidas e revistadas mais de 45 mil pessoas sob o pretexto de mera suspeita baseada na aparência, vestuário ou comportamento. Esse relatório aponta, ainda, que, dessas ações, mais de 37 mil se revelaram gratuitas e arbitrárias, restando justificadas apenas 4 mil detenções. De acordo com Wacquant (2001, p. 35), "uma investigação levada a cabo pelo jornal New York 
Daily News sugere que perto de $80 \%$ dos jovens homens negros e latinos da cidade foram detidos e revistados pelo menos uma vez pelas forças da ordem".

Entretanto, conforme Shecaira (2009), apesar dos reiterados casos de violação de direitos, o programa Tolerância Zero contou com apoio quase que incondicional da mídia, o que permitiu a consolidação desse modelo e a sua contínua expansão, principalmente pelos adeptos do discurso de lei e ordem.

\section{O fortalecimento dos mecanismos de atuação comunitária como alternativa para a superação de processos culturais.}

Segundo o Núcleo de Estudos da Violência da Universidade de São Paulo (NEV-USP) (2009, p. 14), a partir dos estudos de Trojanowicz e Bucqueroux (1999), conceitualmente, polícia comunitária é uma "filosofia e estratégia organizacional que proporcionam uma nova parceria entre a população e a polícia, baseada na premissa de que ambos devem trabalhar, conjuntamente, na construção da segurança pública". Em uma perspectiva operacional, a polícia comunitária é definida como "a filosofia de policiamento adaptada às exigências do público que é atendido, em que o policial presta um serviço completo". Assim, nessa abordagem, "o mesmo policial realiza patrulhas e trabalha em uma mesma área, em uma base permanente, atuando em parceria com a população desse entorno" (NEV-USP, 2009, p. 14).

Para o NEV-USP (2009), Jerome Skolnick e David Bayley são considerados os primeiros pesquisadores de polícia comunitária nos Estados Unidos da América, motivo pelo qual o estudo sobre o tema se iniciará por esses autores. Skolnick e Bayley (2006) apontam que a polícia comunitária representa a perspectiva progressista e mais avançada do policiamento.

Os autores destacam que, "devido ao fato de, no policiamento moderno, o 'policiamento comunitário' ser tão popular - mas tão vago - muitos vão concluir que se trata de um movimento somente retórico - isto é, uma frase de efeito para tornar o policiamento mais palatável”. Assim, um cuidado essencial é a adequada utilização do conceito, para que não se confundam "práticas operacionais com intenções, filosofia, motivação, estilo de gerenciamento, requisitos administrativos e estrutura organizacional" (SKOLNICK; BAYLEY, 2006, p. 17). 
Skolnick e Bayley (2006) ainda alertam que qualquer progresso em relação ao policiamento comunitário se vincula à atribuição de um conteúdo programático. "Ele deve refletir a filosofia no nível de táticas e estratégias de operação", sob pena de se revelar "puro teatro, que talvez até possa ser interessante às próprias forças policiais, mas que terá pouca importância para as comunidades que essas forças se propõem a servir" (SKOLNICK; BAYLEY, 2006, p. 18).

O aumento da responsabilização da polícia se choca em certa medida com crenças típicas das organizações policiais - as subculturas já tratadas -, de que são seus integrantes aqueles que detêm o conhecimento necessário para estabelecer métodos e procedimentos de policiamento, protegendo assim a sociedade. Nesse contexto, segundo Skolnick e Bayley (2006, p. 29), se policiais “desejam gozar de apoio e da cooperação do público, devem estar preparados para ouvir o que a população tem a dizer, mesmo que seja desagradável".

De acordo com Skogan (2008), o policiamento comunitário surgiu entre as décadas de 1970 e 1980, nos Estados Unidos, como uma política pública fruto de um movimento bottom up (SABATIER, 1986), contrária ao então modelo "profissional” dominante, cujas origens são baseadas em experimentos desenvolvidos por Robert Peel, em Londres, e pela polícia de Nova lorque, na década de 1840.

O modelo proposto por Robert Peel, então integrante do parlamento inglês, baseava-se no ideário de que os policiais são pessoas públicas, devidamente remuneradas e destinadas a prestar um atendimento pleno ao cidadão, com vista ao bem-estar da comunidade.

De acordo com Skogan (2008), algumas premissas eram centrais, desde as iniciativas que deveriam ser impulsionadas a partir da descentralização das tomadas de decisão, conferindo assim responsabilidade e autoridade aos policiais da execução - da ponta da linha -, e não somente aos seus comandantes. Outro elemento era a participação da sociedade no diagnóstico dos problemas e na definição de prioridades de atuação da polícia e, por fim, na definição de estratégias pautadas por metodologias próprias da solução de problemas.

De acordo com Ribeiro (2014, p. 527-528), “exatamente por isso, o policiamento comunitário não pode ser entendido como um programa ou uma estratégia, mas sim como 
um processo de reforma organizacional da polícia", uma vez que envolve mudanças na estruturação das instituições e nos processos decisórios que motivam a atuação policial.

A transição esperada envolve uma mudança cultural, com motivação e esforço dos diversos atores e instituições envolvidas. A aplicação do novo modelo de policiamento deve considerar as distintas formas de percepção da realidade, além de fatores que podem se revelar obstáculos para a sua implementação (DURANTE, 2010), sendo que o “policiamento comunitário merece ser celebrado apenas se estiver ligado a um distanciamento das práticas operacionais passadas, e somente se ele refletir uma nova realidade tática e estratégica." (SKOLNICK; BAYLEY, 2006, p. 18).

\section{CONSIDERAÇÕES FINAIS}

O presente artigo buscou compreender a possível relação das subculturas nas organizações policiais e de que maneira interferem na reprodução de comportamentos que ofendem direitos fundamentais, com o objetivo assim de superar a visão exposta por Jorge da Silva (2008), de que as comunidades são vistas como "teatros de operação", como se estivéssemos em uma "guerra" contra o crime e a violência.

Para a compreensão do problema foi necessário o cumprimento de etapas, partindo da relação entre a atuação discricionária da polícia e o monopólio do uso da força, caracterizando o que se denominou de extensão do mandato policial.

Observou-se a problemática dos processos culturais intrínsecos nessas organizações, com características muito peculiares que as tornam agrupamentos, por vezes, hermeticamente fechados, não permitindo desse modo a transição para um modelo policial mais progressista.

Como elemento adicional, foi ainda destacada a influência dos modelos penais expansionistas, em especial o movimento Lei e Ordem e o Programa Tolerância Zero, os quais têm repercutido na difusão de subculturas nas instituições policiais.

A construção e o fortalecimento de ideais democráticos dentro dos organismos policiais, mediante a implantação de um policiamento de proximidade e baseado na resolução pacífica de conflitos, a partir da filosofia de polícia comunitária, é uma realidade presente em diversos países há mais de 40 anos. Apesar de ainda incipiente no país, hoje já 
ocupa todos os espaços de discussão das academias de polícia, motivo pelo qual se traduz como uma oportunidade singular para gestores públicos e comunidade organizada.

Nesse contexto, ao se fortalecer conceitos de proximidade e interação comunitária, a perspectiva trazida originalmente por Robert Peel, de que "a polícia é o povo e o povo é a polícia." (BRASIL, 2013, p. 380), se eleva como uma alternativa alvissareira, apta a superar resistências internas, frutos de códigos de conduta informais nas organizações policiais.

Desse modo, a partir de um novo olhar sobre a polícia, não se terá mais um órgão amparado na cultura de combater o crime e o criminoso. Esse imaginário, materializado em subculturas arraigadas, tem se revelado um verdadeiro obstáculo para a construção de políticas públicas de segurança. A partir da melhor compreensão do fenômeno, estima-se uma mudança de rumos na forma de atuar das organizações policiais, as quais passarão a ser reconhecidas como prestadoras de um serviço público essencial, guardiãs e emancipadoras de direitos humanos.

\section{REFERÊNCIAS}

BITTNER, Egon. As funções da polícia na sociedade moderna: uma revisão dos fatores históricos, das práticas atuais e dos possíveis modelos do papel da polícia. In: BITTNER, Egon. Aspectos do trabalho policial. São Paulo: Edusp, 2003. p. 93-218.

BITTNER, Egon. Introduction. In: BITTNER, Egon. Aspects of police work. Boston: Northeastern University Press, 1990. p. 3-18.

BRASIL. Constituição da República Federativa do Brasil de 1988. Brasília, DF: Presidência da República, 2020. Disponível em: http://www.planalto.gov.br/ccivil_03/constituicao/constituicao.htm. Acesso em: 04 jun. 2021.

BRASIL. Instituto de pesquisa econômica aplicada (Ipea). Fórum Brasileiro de Segurança Pública (FBSP). Atlas da violência 2018. Rio de Janeiro, 2018. Disponível em: http://www.ipea.gov.br/portal/images/stories/PDFs/relatorio_institucional/180604_atlas_ da_violencia_2018.pdf. Acesso em: 11 jun. 2018.

BRASIL. Curso nacional de multiplicador de polícia comunitária. Secretaria Nacional de Segurança Pública. 5. ed. Brasília: Ministério da Justiça, 2013.

CALDEIRA, Teresa Pires do Rio. Direitos humanos ou 'privilégios de bandidos'? Desventuras da democratização brasileira. Novos Estudos Cebrap, n. 30, jul. 1991. p. 162-174. 
CARDIA, Nancy. Pesquisa nacional por amostragem domiciliar sobre atitudes, normas culturais e valores em relação à violação de direitos humanos e violência: um estudo em 11 capitais de Estado. São Paulo: Núcleo de Estudos da Violência-USP, 2012.

DAHRENDORF, Ralf. Law and order. Londres: Stevens and Sons, 1985.

DIAS NETO, Theodomiro. Policiamento comunitário e controle sobre a polícia: a experiência norte-americana. São Paulo: Ibccrim, 2000.

DURANTE, Marcelo Ottoni. Gestão orientada por resultados: cartografia da violência e criminalidade. $O$ público e o privado (UECE), v. 15, jan./jun. 2010. p. 241-272.

ELBERT, Carlos Alberto. O populismo penal: realidade transitória ou definitiva? In: D’AVILA, Fabio Roberto (org.). Direito penal e política criminal no terceiro milênio: perspectivas e tendências. Porto Alegre: EDIPUCRS, 2011. p. 58-67. Disponível em: http://ebooks.pucrs.br/edipucrs/direitopenal.pdf. Acesso em: 29 jul. 2016.

FERRAJOLI, Luigi. Direito e razão: teoria do garantismo penal. São Paulo: Revista dos Tribunais, 2002.

FERREIRA, Helder Rogério Sant'Ana; MARCIAL, Elaine Coutinho. Violência e segurança pública em 2023: cenários exploratórios e planejamento prospectivo. Rio de Janeiro: Ipea, 2015 .

GARLAND, David. A cultura do controle: crime e ordem social na sociedade contemporânea. Rio de Janeiro: Revan, 2008.

GOFFMAN, Erving. Manicômios, prisões e conventos. São Paulo: Perspectiva, 1974.

GOLDSTEIN, Herman. Improving policing: a problem-oriented approach. Crime and Delinquency, v. 25, 1979. p. 236-258.

GOLDSTEIN, Herman. Policiando uma sociedade livre. São Paulo: Edusp, 2003.

HAGEN, Acácia Maria. O trabalho policial: estudo da Polícia Civil do estado do Rio Grande do Sul. São Paulo: IBCCRIM, 2006.

KELLING, Georg L.; MOORE, Mark H. Perspectives on policing: the evolving strategy of policing. Washington, DC: National Institute of Justice, 1988. Disponível em: https://www.innovations.harvard.edu/sites/default/files/114213.pdf. Acesso em: 10 maio 2017.

MILIBAND, Ralph. O estado na sociedade capitalista. 2. ed. Rio de Janeiro: Zahar, 1982.

MONET, Jean-Claude. Polícias e sociedades na Europa. São Paulo: Edusp, 2001. Série Polícia e Sociedade, n. 3. 
MUNIZ, Jacqueline; PROENÇA JÚNIOR, Domício. Mandato policial. In: LIMA, Renato Sérgio de; RATTON, José Luiz; AZEVEDO, Rodrigo Ghiringhelli de. Crime, polícia e justiça no Brasil. São Paulo: Contexto, 2014. p. 405-414.

PONCIONI, Paula Ferreira. Tendências e desafios na formação profissional do policial no Brasil. Revista Brasileira de Segurança Pública, v. 1, n. 1, 2007. p. 22-31.

RATTON, José Luiz. Aspectos organizacionais e culturais da violência policial. In: RATTON, José Luiz; BARROS, Marcelo. Polícia, democracia e sociedade. Rio de Janeiro: Lumen Juris, 2007.

REINER, Robert. A política da polícia. Tradução: Jacy Cardia Ghirotti e Maria Cristina Pereira da Cunha Marques. São Paulo: Edusp, 2004.

REINER, Robert. Policing and the police. In: MAGUIRE, Mike; MORGAN, Rod; REINER, Robert. The Oxford Handbook of Criminology. Oxford: Clarendon, 1994. p. 705-772.

RIBEIRO, Ludmila. Policiamento comunitário. In: LIMA, Renato Sérgio de; RATTON, José Luiz; AZEVEDO, Rodrigo Ghiringhelli de. Crime, polícia e justiça no Brasil. São Paulo: Contexto, 2014. p. 435-444.

SABATIER, Paul A. Top-down and bottom-up approaches to implementation research: a critical analysis and suggested synthesis. Journal of public policy, v. 6, n. 1, 1986. p. 21-48.

SILVA, Jorge da. Criminologia crítica: segurança pública e polícia. Rio de Janeiro: Forense, 2008.

SCHABBACH, Letícia Maria. Com a lei debaixo do braço. Dilemas: Revista de Estudos de Conflito e Controle Social, v. 8, n. 1, jan./mar. 2015. p. 157-188.

SKOGAN, W. G. An overview of community policing: origins, concepts and implementation. In: WILLIAMSON, Tom. The handbook of knowledge-based policing: current conceptions and future directions. Chicago: John Willey \& Sons, 2008. p. 43-57.

SKOGAN, W. G.; FRYDL, K. Fairness and effectiveness in policing: the evidence NRC committee to review research on police policy and practice. Washington D.C.: The National Academies Press, 2004.

SKOLNICK, Jerome H.; BAYLEY, David H. Policiamento comunitário: questões e práticas através do mundo. São Paulo: Edusp, 2006.

TROJANOWICZ, Robert. C.; BUCQUEROUX, Bonnie. Policiamento comunitário: como começar. Rio de Janeiro: Polícia Militar do Estado do Rio de Janeiro, 1994.

UNIVERSIDADE DE SÃO PAULO. Núcleo de estudos da violência. Manual de policiamento comunitário: polícia e comunidade na construção da segurança/ Núcleo de Estudos da Violência da Universidade de São Paulo (NEV/USP). - Dados eletrônicos. 2009. 
WACQUANT, Loïc. Punir os pobres: a nova gestão da miséria nos Estados Unidos. 2. ed. Rio de Janeiro: Revan, 2003.

WILSON, O. W. Administración de la policia. México: Limusa, 1992.

ZAFFARONI, Eugenio Raúl; OLIVEIRA, Edmundo. Criminologia e política criminal. Rio de Janeiro: GZ, 2010.

Recebido em: 05/01/2021

Parecer em: 21/04/2021

Aprovado em: 27/05/2021 